\title{
REFLEXOS DA COVID-19 NO ORÇAMENTO PÚBLICO DO GOVERNO FEDERAL
}

\section{REFLECTIONS OF COVID-19 IN THE FEDERAL GOVERNMENT'S PUBLIC BUDGET}

\author{
JANUÁRIO JOSÉ MONTEIRO \\ Universidade Federal de Santa Catarina (UFSC) \\ Doutorando do PPG em Contabilidade (UFSC)
}

Orcid: https://orcid.org/0000-0002-7000-4256 / E-mail: januariomonteiromonteiro@gmail.com

Campus Universitário, S/N Trindade - Florianópolis - SC CEP: 88970-000

\section{RODRIGO RENGEL}

Universidade Federal de Santa Catarina (UFSC)

Doutorando do PPG em Contabilidade (UFSC)

Orcid: http://orcid.org/0000-0003-1767-1655 / E-mail: rengel.rodrigo@hotmail.com

\section{FABRICIA SILVA DA ROSA}

Universidade Federal de Santa Catarina (UFSC)

Doutora e professora do PPG em Contabilidade (UFSC)

Orcid: https://orcid.org/0000-0003-4212-1065 / E-mail: fabriciasrosa@hotmail.com

\section{ROGÉRIO JOÃO LUNKES}

Universidade Federal de Santa Catarina (UFSC)

Doutor e professor do PPG em Contabilidade (UFSC)

Orcid: https://orcid.org/0000-0003-4232-5746 / E-mail: rogeriolunkes@hotmail.com

\section{ANA PAULA HASKEL}

Universidade Federal de Santa Catarina (UFSC)

Mestre pelo PPG em Contabilidade (UFSC)

Orcid: https://orcid.org/0000-0002-2517-6147 / E-mail: anaphaskel@gmail.com

Submissão: 03/06/2020. Revisão:13/10/2020. Aceite: 05/11/2020. Publicação: 29/12/2020.

DOI: http://dx.doi.org/10.22277/rgo.v14i1.5560

\section{RESUMO}

Esta pesquisa tem como objetivo examinar o impacto da pandemia da COVID-19 no orçamento público do Governo Federal. O delineamento metodológico adotado foi o descritivo, qualitativo e com análise documental. A análise documental foi dividida em duas fases: (i) Análise das alterações na arrecadação de tributos federais; e (ii) Análise das alterações das despesas por meio de Medidas Provisórias. Os resultados evidenciam que em relação aos tributos federais, o Governo Federal postergou os prazos de vencimento do Simples Nacional e MEI (DAS), da PIS/PASEP e COFINS. Além da redução para zero da alíquota do IOF e do IPI referente aos produtos de combate ao COVID-19. Quanto as despesas, o Governo Federal autorizou a abertura de créditos extraordinários no valor de R\$ 252,3 bilhões. Este valor representa um aumento de $4 \%$ nas despesas previstas no orçamento público. Essas despesas a princípio estão direcionadas para auxílio de pessoas em situação de vulnerabilidade $(50 \%)$, proteção do emprego e concessão de financiamento às empresas (33\%), e em torno de $17 \%$ especificamente para a saúde. A pesquisa gera implicações ao revelar que a participação do Estado na economia precisa ser notória frente à crise COVID-19, seja por salvaguardar os direitos essenciais à vida, por resguardar o emprego e por buscar soluções tempestivas.

Palavras-chave: COVID-19. Tributos federais. Orçamento Público. Governo Federal. 
Januário José Monteiro, Rodrigo Rengel, Fabricia Silva da Rosa, Rogério João Lunkes e Ana Paula Haskel

\begin{abstract}
This research aims to examine the impact of the COVID-19 pandemic on the federal government's public budget. To this end, qualitative research with documentary analysis was adopted. The document analysis was divided into two phases: (i) Analysis of changes in the collection of federal taxes; and (ii) Analysis of changes in expenses through Provisional Measures. The results show that in relation to federal taxes, the Federal Government has postponed the maturity terms of Simples Nacional and MEI (DAS), PIS / PASEP, and COFINS. In addition to the reduction to zero of the IOF and IPI tax rate for products to combat COVID-19. Regarding expenses, the Federal Government authorized the opening of extraordinary credits in the amount of $R \$ 252.3$ billion. This value represents a $4 \%$ increase in the expenses foreseen in the public budget. In principle, these expenses are aimed at helping people in vulnerable situations (50\%), job protection and granting financing to companies (33\%), and around $17 \%$ specifically for health. The research has implications for revealing that the state's participation in the economy needs to be notorious in the face of the COVID-19 crisis, either by safeguarding the essential rights to life, by safeguarding employment, and by seeking timely solutions.
\end{abstract}

Keywords: COVID-19. Federal taxes. Public budget. Federal government.

\title{
1 INTRODUÇÃO
}

Há décadas as infecções por Coronavírus são conhecidas pela comunidade científica. Sabe-se da existência de sete principais tipos de Coronavírus Humano, sendo que quatro causam doenças respiratórias leves, e outras três agudas. E a COVID-19 está entre esses que provocam doenças agudas (RAFAELL et al., 2020). A COVID-19 teve origem em Wuhan, na China, os registros iniciais são de dezembro de 2019, sendo que no dia 11 de março de 2020 foi declarada como pandemia pela Organização Mundial de Saúde - OMS (DJALANTE et al., 2020). Isto porque atingiu os critérios epidemiológicos de pandemia, ou seja, mais de 100.000 pessoas infectadas em 100 países (CALLAWAY, 2020). Em 25 de outubro de 2020, registra-se mais de 43 milhões de pessoas infectadas e mais de 1 milhão de mortes, espalhadas por todos os continentes (OMS, 2020).

O risco de transmissão da COVID-19 é considerado incontrolável até o momento por não haver cura, e disponibilidade de vacinas pelos próximos meses (ATLURI; MANCHIKANTI; HIRSCH, 2020), o que promove pânico global (CHIOLERO, 2020). Consequências econômicas já são percebidas, como o preço do petróleo, o mercado de ações, ouro, moedas e quase todas as áreas do mercado global são afetadas (XIANG et al., 2020). Os efeitos desta pandemia podem ser considerados o "maior risco econômico global" dos últimos anos (CANDEAIS; MORHARD, 2020).

Em busca de soluções para amenizar os efeitos do problema, governos em todo mundo adotam o isolamento social como medida de segurança, seguindo o caso chinês, com utilização da quarentena de contenção da COVID-19 (OMS, 2020). Entretanto, o isolamento social traz consigo consequências econômicas, já que as empresas são impossibilitadas de produzirem ou prestarem seus serviços. Isto faz com que países afetados pela pandemia adotem medidas para combater os efeitos econômicos da crise como, a postergação e isenção de tributos, entre outras medidas.

Por exemplo, nos Estados Unidos, o governo cortou os impostos sobre salários (TANNE, 2020); na China, o governo isentou uma ampla gama de serviços do Imposto de Valor 
Agregado (KPMG CHINA; LU, 2020); a Itália estendeu os prazos fiscais e ampliou o fundo de auxílio de renda aos trabalhadores demitidos (GOPINATH, 2020); e o Brasil postergou prazos de recolhimento de impostos para as empresas, e possibilitou o saque do Fundo de Garantia por Tempo de Serviço (FGTS) por trabalhadores (BRASIL, 2020b).

Entretanto, essas medidas têm um paradoxo que colocam em "cheque" a capacidade fiscal dos governos, já que de um lado tem-se a redução de receitas oriundas de tributos; e de outro, o aumento de gastos sanitários e sociais. Ou seja, além da frustação de receitas provenientes da postergação e redução de tributos, há um aumento de gastos governamentais com saúde, pois o sistema sanitário é pressionado, já que há um aumento exponencial do número de casos, que excedem a capacidade instalada do sistema de saúde. Por exemplo, os países têm tido a necessidade de aumentar o número de leitos em Unidade de Terapia Intensiva (UTI) dos hospitais, testes ambulatoriais, contratação de pessoal em saúde, compra de materiais e equipamentos, entre outros.

Rafaell et al. (2020) entendem que a experiência internacional tem demonstrado três grandes estratégias para a contenção da curva ascendente de casos e mortes por COVID-19. Essas estratégias devem levar a ampliação da capacidade assistencial do sistema de saúde, e são elas: (i) Ampliação da testagem dos casos suspeitos com entrega rápida dos resultados; (ii) Identificação dos comunicantes da doença com ulterior e imediato isolamento domiciliar; e (iii) Investimentos voltados a proteção dos profissionais de saúde; além do deslocamento de profissionais voltados à assistência, ao monitoramento e à implementação de estratégias de controle comunitário.

Para atender a estas novas demandas na área da saúde e sociais, os governos precisam alterar seu planejamento orçamentário. Isto porque a pandemia gera efeitos econômicos que precisam ser gerenciados. Assim, os aspectos econômicos tornam-se uma das principais áreas de pesquisa (HALEEM et al., 2020). Isso porque de um lado, se tem um "freio" nos ingressos econômicos, e do outro, aumento expressivo em gastos sanitários e sociais.

Embora essenciais para conter a pandemia, as medidas como as ações de isolamento social e aumento da capacidade sanitária instalada, trazem reflexos econômicos relevantes. Pois estes demandam ações emergenciais para evitar ou reduzir o número vítimas fatais e de falências econômicas (empresariais e pessoais), bem como, garantir fluxo econômico contínuo (BALDWIN, 2020). Medidas como, transferências monetárias, subsídios salariais e isenção de impostos são algumas das possibilidades adotadas até o momento, para manter a economia (GASPAR; MAURO, 2020). Entretanto, ainda são muitos os desafios para manter o equilíbrio do orçamento público, e lidar com o risco econômico presente e futuro.

Portanto, o equilíbrio no orçamento público pode ser um desafio em países emergentes como o Brasil. Isto porque tem altas demandas por serviços públicos, infraestrutura deficitária e recursos financeiros limitados, além de um alto custo da dívida pública (SAWHNEY, 2018). Em momentos de crise, como da COVID-19, manter o equilíbrio orçamentário se torna ainda mais essencial e paradoxal, pois, de um lado tem recessão econômica e retração de receitas orçamentárias, e de outro, um aumento expressivo da demanda por serviços sanitários, o que pode levar o sistema ao colapso, com riscos fiscais futuros (dívida) e incapacidade de atender a população.

Nesta perspectiva, na presente pesquisa tem-se como questão norteadora: qual o impacto da pandemia COVID-19 no orçamento público do Governo Federal? Para responder a esta pergunta, o estudo tem como objetivo examinar o impacto da pandemia COVID-19 no orçamento público do Governo Federal. 
Como justificativas, destaca-se a importância de se estudar o tema por se tratar de um problema que não atingiu somente o Brasil, mas todo o planeta (OMS, 2020). Assim, como pelos efeitos econômicos negativos ocasionados pela COVID-19 e a necessidade de investigações sobre como melhorar tais cenários (HALEEM et al., 2020).

O estudo busca trazer uma contribuição prática para os processos decisórios sobre finanças públicas. Primeiro, ao sugerir que o equilíbrio do orçamento é complexo em países emergentes e com dimensões populacionais e regionais de grande escala, como por exemplo o Brasil. Segundo, por revelar que as reservas de contingência têm um papel importante em momentos como este. Em tempos de emergência ou calamidade pública, a gestão orçamentária torna-se ainda mais complexa, e demanda do gestor público um conhecimento holístico sobre o fluxo econômico, o equilíbrio orçamentário, e os impactos sociais. Implicações teóricas também são esperadas, isto porque busca entender os impactos na COVID-19 na economia.

\section{REFERENCIAL TEÓRICO}

\subsection{ORÇAMENTO PÚBLICO}

No Brasil, a Constituição Federal (CF) de 1988 prevê que compete à União, aos Estados e ao Distrito Federal legislar concorrentemente sobre o orçamento, de maneira a prever receitas e estimar despesas, e legislar sobre execução e alterações orçamentárias. No orçamento público são instrumentalizadas as políticas públicas que permitem ao governo planejar e garantir o direito dos cidadãos. Conforme o Art. $2^{\circ}$ da Lei $n=4320 / 64$, a Lei do Orçamento conterá a discriminação da receita e despesa de forma a evidenciar a política econômico-financeira e o programa de trabalho do governo. Para tanto, devem ser obedecidos os princípios de unidade, universalidade e anualidade.

O orçamento também deve seguir metas e limites, conforme preconizado pela Lei de Responsabilidade Fiscal (LRF). Esta Lei estabelece normas de finanças públicas voltadas para a responsabilidade na gestão fiscal, impõe limites de gastos com pessoal e dívida (BRASIL, 2011). Assim, a LRF encontra-se associada aos conceitos de planejamento, controle, transparência e responsabilidade (LEITE FILHO et al., 2018).

Esse marco regulatório prevê que o orçamento serve para instrumentalizar políticas públicas, sendo composto de três peças: O Plano Plurianual (PPA), a Lei de Diretrizes Anuais (LDO) e a Lei Orçamentária Anual (LOA). O PPA, segundo $\$ 1^{\circ}$ do Art.165 da CF, estabelece, de forma regionalizada, as diretrizes, objetivos e metas da administração pública para os quatro anos do mandado da presidência, e apresenta programas, projetos e atividades que o governo tem intenção de elaborar e concluir. A LDO, é o elo entre o PPA e a LOA, e compreende as metas e prioridades da administração pública federal, orienta a elaboração da LOA, dispõe sobre as alterações na legislação tributária, e estabelece a política de aplicação das agências financeiras oficiais de fomento. E a LOA, é o orçamento em si, onde se estima a receita e fixa a despesa para o período de um ano, visando alcançar os objetivos pré-estabelecidos no PPA e LDO. Esses instrumentos orçamentários (PPA, LDO, LOA) devem seguir as regras impostas pela Lei de Responsabilidade Fiscal (LRF).

O orçamento tem caráter de previsão de receitas e despesas para um exercício social, sendo assim, pode-se ter necessidade de alterações no decorrer de sua execução. Visando possibilitar esta alteração, a Lei no 4320/64 prevê a possibilidade de abertura de Créditos Adicionais. Os Créditos Adicionais são as autorizações de alteração de despesa não computadas ou insuficientemente dotadas na Lei de Orçamento (LOA). Classificam-se em: (a) 
suplementares: destinados a reforço de dotação orçamentária, e encaminhado ao Congresso Nacional pelo Presidente da República por meio de Projeto de Lei; (b) especiais: destinados a despesas para as quais não haja dotação orçamentária específica, e encaminhado ao Congresso Nacional pelo Presidente da República por meio de Projeto de Lei, (c) extraordinários: destinados a despesas urgentes e imprevistas, em caso de guerra, comoção intestina ou calamidade pública; encaminhado ao Congresso Nacional pelo Presidente da República por meio de Medida Provisória (BRASIL, 2020).

As medidas de abertura de crédito extraordinário permitem flexibilizar o orçamento público, quando atribui ao Poder Executivo do Governo Federal autorizar a criação de despesas urgentes e imprevistas, em caso de guerra, comoção intestina ou calamidade pública por meio de Medida Provisória, sem a necessidade de autorização prévia do Poder Legislativo. Conforme a CF, a União, mediante lei complementar, poderá constituir despesas extraordinárias, decorrentes de situação de emergência e urgência (calamidade pública, de guerra externa ou sua iminência). Logo, para abertura de crédito extraordinário, é necessário que seja deflagrado essas situações de emergência ou urgência.

Por exemplo, no caso da pandemia COVID-19 a abertura de créditos extraordinários ocorre para auxiliar o Governo Federal a enfrentar as consequências sociais e econômicas. Esse mecanismo de alteração orçamentária pode ocorrer, pois o Congresso Nacional reconheceu estado de calamidade pública, válido até dezembro de 2020 . O que permite de acordo com a LRF a dispensa do cumprimento de meta fiscal, e o contingenciamento de despesas caso não exista receitas suficientes, além de ser dispensado de cumprir a "regra de ouro", prevista no Art. 167 da CF. Consequentemente, sem a observação da regra de ouro, é possível o Governo Federal realizar operações de créditos que excedam o montante das despesas de capital.

\subsection{ORÇAMENTO PÚBLICO EM CASO DE CALAMIDADE PÚBLICA}

Em épocas de crise, como da emergência sanitária e econômica proveniente da COVID19, o equilíbrio orçamentário pode ser ameaçado, tanto pela frustação de receitas, quanto pela necessidade do aumento de despesas. Em síntese, os investimentos podem levar a um melhor desempenho dos serviços prestados pelo governo, desde que haja equilíbrio entre receitas e despesas públicas. Mas em épocas de emergência há vários fatores que podem levar ao desequilíbrio orçamentário e à ameaça na equidade social ao mesmo tempo. Por isso, são necessárias medidas de gestão que permitam flexibilizar e melhorar o orçamento, ao mesmo tempo em que atende a população em sua emergência sanitária e social.

Neste ambiente complexo é fundamental entender os reflexos da pandemia, compreendendo o fluxo econômico e os efeitos orçamentários em tempos de emergência COVID-19. O que se sabe sobre o fluxo econômico é que a economia moderna é composta por uma rede interconectada por diversas empresas, de diferentes setores, funcionários, fornecedores, consumidores, agências financeiras, entre outros. Com isto, se houver um rompimento em algum dos elos das relações por políticas de contenção de doenças, isto terá um efeito em cascata (BALDWIN; DI MAURO, 2020).

Amenizar essas interrupções econômicas requer capacidade financeira e flexibilidade orçamentária por parte do governo. Essas alterações na gestão de recursos são feitas por meio de políticas públicas. Diante da emergência causada pela pandemia, o Governo Federal do Brasil, institui medidas para amenizar as interrupções econômicas. Por meio da Lei no 13.979 (de 6 de fevereiro de 2020) foram tratadas algumas medidas de flexibilização do orçamento 
para o Ministério da Saúde e gestores locais de saúde como, por exemplo, dispensa de licitação e facilitação na contratação de pessoal da saúde.

A Lei no 4320/64 prevê abertura de créditos adicionais pelo poder executivo sem a necessidade de aprovação prévia do legislativo. Neste sentido, foram publicadas Medidas Provisórias (929, 935, 937, 939, 943, 959) que permitem a abertura de Crédito Adicional Extraordinário para atuar no combate à pandemia COVID-19.

Apesar de haver a possibilidade de o Poder Executivo Federal alterar a LOA sem autorização prévia do Poder Legislativo, tramita no Congresso Nacional a proposta de Ementa Constitucional, o chamado "Orçamento de Guerra", que especifica e dá providências para gastos para combate ao COVID-19. O Orçamento de Guerra será abordado em mais detalhes na sequência.

\subsection{ORÇAMENTO DE GUERRA (EC 106/2020)}

Em 07 de maio de 2020 foi aprovada a Emenda Constitucional (EC) no 106/2020, denominada "Orçamento de Guerra", que "Institui regime extraordinário fiscal, financeiro e de contratações para enfrentamento da calamidade pública nacional decorrente de pandemia internacional; e dá outras providências".

O projeto, entre outras medidas, visa a separação dos gastos realizados para o combate à COVID-19 do Orçamento Geral da União (OGU), trata do Regime Extraordinário Fiscal, Financeiro e de Contratações, e trata e prevê agilidade nas compras, obras e contratações de pessoal temporário e serviços. A EC 106 é composta de 11 artigos que tratam de prazos, propósito, responsabilidade, despesa, receita, prestação de contas, operações de crédito, Banco Central e disposições gerais, conforme Quadro 1.

Conforme o Quadro 1, a EC 106/2020 possibilita a flexibilização do orçamento, primeiramente por permitir a abertura de crédito adicional extraordinário, e o não cumprimento da regra de ouro do orçamento público. Também se observa a possibilidade de alterações de valores das receitas e despesas. Assim, quanto a receita permite a concessão de incentivos e benefícios tributários, bem como o recebimento de benefícios. Quanto a despesa possibilita a simplificação da contratação de pessoal, em caráter temporário e emergencial, e de obras, serviços e compras que assegurem, quando possível, competição e igualdade de condições a todos os concorrentes.

Vale destacar que segundo a LRF, no seu Art. no 34, o Banco Central do Brasil não emitirá títulos da dívida pública. No entanto, na EC 106/2020 no seu Art. no 7, prevê que o Banco Central do Brasil, limitado ao enfrentamento da calamidade pública nacional, e com vigência e efeitos restritos ao período de sua duração, fica autorizado a comprar e vender: I títulos de emissão do Tesouro Nacional, nos mercados secundários local e internacional; e II os ativos, em mercados secundários nacionais no âmbito de mercados financeiros, de capitais e de pagamentos.

A EC 106 é também marco histórico no País, já que se diferencia das aberturas de créditos extraordinários anteriores, ao segregar as alterações do orçamento da pandemia COVID-19 do orçamento principal do Governo Federal. Ou seja, o Governo Federal terá basicamente dois orçamentos, o do exercício 2020 e o Orçamento de Guerra. Uma síntese dos artigos e de seus conteúdos estão descritos no Quadro 1. 
Reflexos da COVID-19 no orçamento público do Governo Federal

Quadro 1 - EC 106/05/2020

\begin{tabular}{|c|c|c|}
\hline Elemento & Artigo & Conteúdo \\
\hline Prazos e vigência & $\begin{array}{l}\text { Art. 1‥ } \\
\text { Art. 11ㅇ. }\end{array}$ & $\begin{array}{l}\text { - Durante a vigência de estado de calamidade pública nacional reconhecida } \\
\text { pelo Congresso Nacional }\end{array}$ \\
\hline Propósito & Art. 20. & $\begin{array}{l}\text { - Exclusivo de enfrentamento do contexto da calamidade e de seus efeitos } \\
\text { sociais e econômicos; } \\
\text { - Simplificados de contratação de pessoal, em caráter temporário e } \\
\text { emergencial, e de obras, serviços e compras que assegurem, quando } \\
\text { possível, competição e igualdade de condições a todos os concorrentes. }\end{array}$ \\
\hline Responsabilidade & Art. 3ㅇ. & $\begin{array}{l}\text { - As proposições legislativas e os atos do Poder Executivo com propósito } \\
\text { exclusivo de enfrentar a calamidade e suas consequências sociais e } \\
\text { econômicas. }\end{array}$ \\
\hline Despesa & Art. 3ㅇ. & $\begin{array}{l}\text { - Não impliquem despesa permanente; } \\
\text { - Permite a criação, expansão ou aperfeiçoamento de ação governamental } \\
\text { que acarrete aumento de despesa. }\end{array}$ \\
\hline Receita & $\begin{array}{l}\text { Art. 3ㅇ. } \\
\text { Art. } 4 ․\end{array}$ & $\begin{array}{l}\text { - Concessão ou ampliação de incentivo ou benefício de natureza tributária } \\
\text { da qual decorra renúncia de receita (incluindo a pessoa jurídica em débito } \\
\text { com o sistema da seguridade social); } \\
\text { - Recebimento de benefícios creditícios, financeiros e tributários, direta ou } \\
\text { indiretamente, no âmbito de programas da União com o objetivo de } \\
\text { enfrentar os impactos sociais e econômicos da pandemia, e está } \\
\text { condicionado ao compromisso das empresas de manutenção de empregos, } \\
\text { na forma dos respectivos regulamentos. }\end{array}$ \\
\hline $\begin{array}{l}\text { Prestação de } \\
\text { contas }\end{array}$ & Art. $5^{\circ}$ & $\begin{array}{l}\text { - O Ministério da Economia deverá, a cada } 30 \text { (trinta) dias, relatório contendo } \\
\text { os valores e o custo das operações de crédito; } \\
\text { - Constar de programações orçamentárias específicas ou contar com } \\
\text { marcadores que as identifiquem; } \\
\text { - Ser separadamente avaliadas na prestação de contas do Presidente da } \\
\text { República. }\end{array}$ \\
\hline $\begin{array}{l}\text { Operações de } \\
\text { crédito }\end{array}$ & Art. $6^{\circ}$ & $\begin{array}{l}\text { - Os recursos decorrentes de operações de crédito realizadas para o } \\
\text { refinanciamento da dívida mobiliária poderão ser utilizados também para o } \\
\text { pagamento de seus juros e encargos. }\end{array}$ \\
\hline Banco Central & $\begin{array}{l}\text { Art. } 70 \\
\text { Art. } 8^{\circ}\end{array}$ & $\begin{array}{l}\text { - Comprar e vender títulos de emissão do Tesouro Nacional; } \\
\text { - Publicar diariamente as operações realizadas, de forma individualizada } \\
\text { Presidente do Banco Central do Brasil prestará contas ao Congresso } \\
\text { Nacional; } \\
\text { - A alienação de ativos adquiridos pelo Banco Central do Brasil editará } \\
\text { regulamentação sobre exigências de contrapartidas. }\end{array}$ \\
\hline Disposições gerais & $\begin{array}{l}\text { Art. } 9^{\circ} \\
\text { Art. } 10 \circ \text {. } \\
\text { Art. } 110 \text {. }\end{array}$ & $\begin{array}{l}\text { - Irregularidades ou descumprimentos de limites; } \\
\text { - Convalidados os atos de gestão praticados a partir de } 20 \text { de março de } 2020 . \\
\text { - A EC ficará automaticamente revogada na data do encerramento do estado } \\
\text { de calamidade pública. }\end{array}$ \\
\hline
\end{tabular}

Fonte: Brasil (2020a). 


\section{PROCEDIMENTOS METODOLÓGICOS}

A pesquisa classifica-se como descritiva, de caráter qualitativo, operacionalizada por meio da análise documental das receitas e despesas propostas nas Medidas Provisórias que alteram o orçamento para o enfrentamento da pandemia, além da observação da Lei Orçamentária Anual (LOA, 2020). Os dados referentes ao orçamento público foram obtidos no portal de transparência e no portal da Câmara dos Deputados do governo federal no período de $17 / 04 / 2020$ a $28 / 04 / 2020$. A busca no portal de transparência do governo federal, e no portal da Câmara dos Deputados do governo federal. A pesquisa seguiu duas etapas de análise, conforme Figura 1.

Figura 1 - Fases de análise da pesquisa

Fase 1

- Análise das alterações na arrecadação de tributos federais

Fase 2

- Análise das alterações das despesas

Fonte: elaborada pelos autores (2020).

Na primeira etapa, procedeu-se a leitura e interpretação das resoluções sobre os tributos federais, com as alterações dos prazos. As categorias de análise correspondem aos tributos federais: (i) Simples Nacional; (ii) Contribuições (PIS/PASEP e COFINS); (iii) IOF; (iv) IPI; (v) IRPJ e CSLL e o orçamento público. A análise referente aos tributos envolveu as alterações de prazos de vencimento e a redução das alíquotas à zero de produtos médicos, essenciais ao combate à pandemia. Já a análise do orçamento público consistiu na compreensão das novas previsões de despesas, ancoradas em programas que visam o enfrentamento à COVID-19. Quanto aos tributos, o simples nacional incorpora tanto tributos federais quanto estaduais, assim, para esta análise considerou-se apenas os tributos federais

Na segunda, examina-se as ações orçamentárias de enfrentamento à pandemia da COVID-19. Observando os créditos extraordinários abertos por meio de Medidas Provisórias para o combate à pandemia da COVID-19 (MP's: 929, 935, 937, 939, 943, 959).

\section{ANÁLISE E DISCUSSÃO DOS RESULTADOS}

\subsection{ALTERAÇÕES NOS TRIBUTOS FEDERAIS DEVIDO A PANDEMIA DA COVID-19}

A primeira categoria corresponde aos tributos federais incluídos no simples nacional. De acordo com a Lei Complementar no 123 de 2006 e a Resolução CGSN no 140/18, o documento único de arrecadação (DAS) comporta tanto os tributos federais quanto o estadual e municipal. Estes por sua vez, em condições normais são recolhidos até o vigésimo (20) dia do mês subsequente ao que a empresa auferiu a receita bruta (LC 123, 2006). No entanto, em função dos impactos da pandemia da COVID-19, a parcela de recolhimento dos tributos sob tutela da federação (IRPJ, IPI, CSLL, COFINS, PIS/Pasep) tiveram seus prazos de vencimento prorrogados por 6 meses (CGSN 154, 2020). O mesmo ocorreu com o microempreendedor individual (MEI). Apresenta-se, no Quadro 2, os prazos de vencimento de tributos federais. 
Reflexos da COVID-19 no orçamento público do Governo Federal

Quadro 2 - Vencimento de tributos federais

\begin{tabular}{|c|c|c|}
\hline Período Apuração & Vencimento Original & Novo vencimento Tributos Federais \\
\hline Março & $20 /$ abril & $20 /$ outubro \\
\hline Abril & $20 /$ maio & $20 /$ novembro \\
\hline Maio & $22 /$ junho & $21 /$ dezembro \\
\hline
\end{tabular}

Fonte: Resolução CGSN no 154/2020 (BRASIL, 2020q).

Ao considerar que a guia de pagamento do Simples Nacional (PGDAS) antes dos impactos da Pandemia da COVID-19 comportava tanto tributos federais quanto estadual e municipal, e que a Resolução CGSN no 154, de 03 de abril de 2020 segregou a prorrogação dos prazos de vencimento dos tributos federais em 6 meses e do estadual e municipal em 3 meses, a receita federal informou que está sendo adaptado a possibilidade de geração de duas DAS com prazos distintos. "Assim que o PGDAS-D estiver ajustado, novas orientações serão divulgadas. Neste momento, a opção "Gerar DAS" do aplicativo foi alterada [...]".

A segunda categoria refere-se às contribuições (PIS/Pasep e COFINS), o recolhimento está condicionado ao regime tributário ao qual a empresa é optante. Assim, tanto para empresas do regime cumulativo (Lei no 9718/1998) quanto para as do regime não cumulativo (Lei no 10.833/2003), as contribuições referentes ao PIS/Pasep (Lei no 10.637/2002), e ao COFINS (Lei no 10.833/2003) das competências de abril e maio, em função da pandemia da COVID-19 tiverem seus prazos de vencimento postergados para agosto e outubro, respectivamente (Portaria no 136/2020). Ainda em relação a estas contribuições, outra medida nessa direção foi o estabelecimento temporário de alíquota zero (até 30 de setembro) referente à receita decorrente da venda de sulfato de zinco como aponta o Decreto no 10.318/2020:

Art. 1o Ficam reduzidas a zero as alíquotas da Contribuição para o PIS/Pasep, da Contribuição para o Financiamento da Seguridade Social - Cofins, da Contribuição para o PIS/Pasep-Importação e da Cofins-Importação incidentes sobre a receita decorrente da venda no mercado interno e sobre a operação de importação de sulfato de zinco para medicamentos utilizados em nutrição parenteral, classificado nos seguintes códigos:

I - 3003.90.99 da Tabela de Incidência do Imposto sobre Produtos Industrializados TIPI - medicamento a granel; e II - 3004.90.99 da TIPI - medicamento em doses.

O Imposto sobre Operações Financeiras (IOF) se enquadra como terceira categoria de análise. Perante o Decreto no 10.305/2020, a pandemia da COVID-19 motivou o Governo a reduzir a zero as alíquotas do IOF de operações de crédito, no período de 90 dias (entre 03 de abril de 2020 e 03 de julho de 2020) relativas a:

\footnotetext{
I - Operação de empréstimo, sob qualquer modalidade, inclusive abertura de crédito; II - Operação de desconto, inclusive na de alienação a empresas de factoring de direitos creditórios resultantes de vendas a prazo;

III - Adiantamento a depositante;

IV - Empréstimos, inclusive sob a forma de financiamento, sujeitos à liberação de recursos em parcelas, ainda que o pagamento seja parcelado;

$V$ - Excessos de limite, ainda que o contrato esteja vencido;

VI - Operações de crédito, quando o mutuário for pessoa jurídica optante pelo Simples Nacional;

VII - Operações de financiamento para aquisição de imóveis não residenciais, em que o mutuário seja pessoa física.
} 
Estas alterações com base no Decreto no 10.305/2020 reduzem o custo das operações de crédito. Com isto, estima-se que o impacto da desoneração seja de R\$ 7 bilhões (BRASIL, 2020).

A quarta categoria se refere ao Imposto sobre Produtos Industrializados (IPI). O Decreto no 10.302/2020 publicado na Edição Extra do DOU de 01 de abril de 2020, reduz a zero (até 30 de setembro de 2020) as alíquotas do IPI de produtos com artigos de laboratório ou de farmácia (sob o TIPI, 3926.90.40), luvas, mitenes e semelhantes, exceto para cirurgia (sob o TIPI 4015.19.00) e termômetros clínicos (sob o TIPI, 9025.11.10), utilizados para o combate e controle da COVID-19. A estimativa é que a medida gere um impacto fiscal de R\$ 26,6 milhões para os cofres públicos (BRASIL, 2020). A partir de 10 de outubro de 2020, são restabelecidas as alíquotas do IPI anteriores ao Decreto no 10.302/2020.

$\mathrm{Na}$ quinta categoria de análise, os tributos incidentes sobre o lucro líquido (IRPJ e CSLL), que não sofreram alterações até 30 de abril de 2020.

Essas ações na arrecadação dos tributos trazem reflexos tanto no calendário, conforme Quadro 2, quanto na distribuição entre as unidades do governo, e no valor total da arrecadação do governo federal para os próximos meses de 2020. Essa postergação de arrecadação pode trazer reflexos relevantes no fluxo financeiro dos cofres públicos.

Observa-se, que a alteração das receitas afetou a distribuição da responsabilidade de arrecadação entre os órgãos da União. Isso significa que as receitas foram redirecionadas, e assim cada órgão (Unidade Orçamentária ou Administrativa) realiza atos de gestão orçamentária, financeira e/ou patrimonial, e como consequência, estará sujeito a tomada de contas anual na conformidade do disposto nos artigos 81 e 82 do Decreto-Lei no 200, de 25 de fevereiro de 1967 (PORTAL DA TRANSPARÊNCIA, 2020b). Essas alterações podem ser observadas na Figura 2.

Figura 2 - Arrecadação do Governo Federal por órgão para 2020

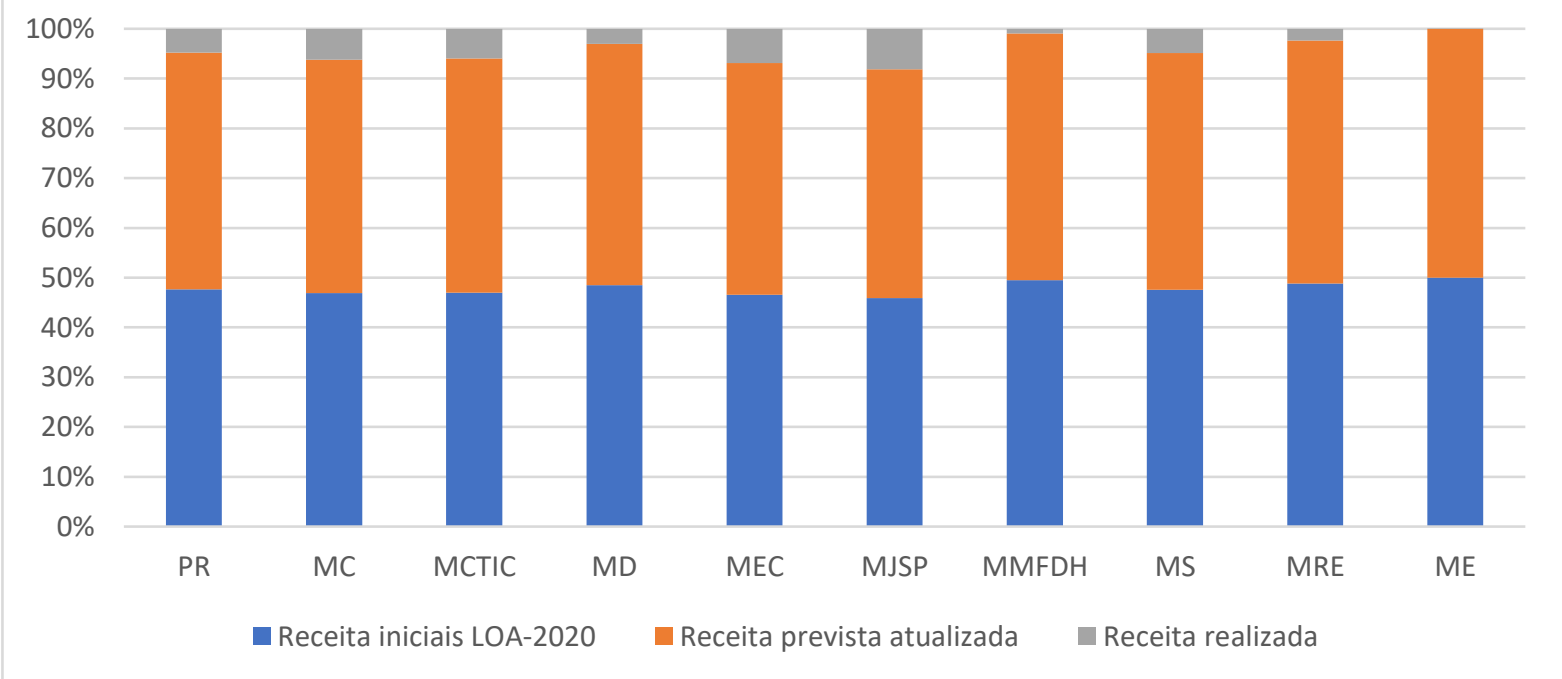

Nota: PR = Presidência da República; $M C=$ Ministério da Cidadania; MCTIC = Ministério da Ciência, Tecnologia, Inovações e Comunicações; $\mathrm{MD}=$ Ministério da Defesa; $\mathrm{MEC}=$ Ministério da Educação; MJSP = Ministério da Justiça e Segurança Pública; MMFDH = Ministério da Mulher, Família e Direitos Humanos; MS = Ministério da Saúde; MRE = Ministério das Relações Exteriores; ME = Ministério da Economia.

Fonte: elaborada pelos autores (2020).

Na Figura 2, observa-se baixa representatividade das receitas realizadas em relação a arrecadação prevista. O que pode ser explicado pelo período de análise (primeiro quadrimestre de 2020), porém pode também ser um indicativo de frustação de receitas, e um possível reflexo da postergação dos impostos que tinham previsão de ingresso para abril, e 
Reflexos da COVID-19 no orçamento público do Governo Federal

que foram postergados com a Resolução CGSN no 154/2020. Na Tabela 1, apresenta-se o detalhamento das receitas previstas e realizadas por órgão do governo federal.

Tabela 1 - Resumo das Receitas previstas e realizadas do Governo Federal em 2020

\begin{tabular}{|c|c|c|c|}
\hline Órgão superior & $\begin{array}{l}\text { Receita iniciais LOA- } \\
2020\end{array}$ & $\begin{array}{c}\text { Receita prevista } \\
\text { atualizada }\end{array}$ & $\begin{array}{c}\text { Receita realizada } \\
\text { Até } 17.04 .20 \\
\end{array}$ \\
\hline Presidência da República (PR) & $10.949 .893 .944,00$ & 10.949.893.944,00 & $1.093 .593 .148,49$ \\
\hline Ministério da Cidadania (MC) & $3.208 .425 .425,00$ & $3.208 .425 .425,00$ & $427.647 .213,04$ \\
\hline $\begin{array}{l}\text { Ministério da Ciência, Tecnologia, } \\
\text { Inovações e Comunicações } \\
\text { (MCTI) }\end{array}$ & 11.273.749.096,00 & 11.273.749.096,00 & $1.433 .159 .748,95$ \\
\hline Ministério da Defesa (MD) & $58.168 .386 .807,00$ & $58.168 .386 .807,00$ & $3.648 .162 .783,76$ \\
\hline Ministério da Educação (MEC) & $55.138 .538 .014,00$ & $55.138 .538 .014,00$ & 8.191.466.357,93 \\
\hline $\begin{array}{l}\text { Ministério da Justiça e Segurança } \\
\text { Pública (MJSP) }\end{array}$ & $8.364 .629 .283,00$ & $8.364 .629 .283,00$ & $1.489 .598 .467,89$ \\
\hline $\begin{array}{l}\text { Ministério da Mulher, Família e } \\
\text { Direitos Humanos (MMFDH) }\end{array}$ & $217.236 .207,00$ & $217.236 .207,00$ & 4.094.102,20 \\
\hline Ministério da Saúde (MS) & 7.811.670.316,00 & 7.811.670.316,00 & $800.940 .981,81$ \\
\hline $\begin{array}{l}\text { Ministério das Relações } \\
\text { Exteriores (MRE) }\end{array}$ & $1.449 .976 .625,00$ & $1.449 .976 .625,00$ & $70.360 .001,29$ \\
\hline Ministério da Economia (ME) & $2.665 .393 .025 .638,00$ & 2.665.393.025.638,00 & 255.606.559.835,33 \\
\hline TOTAL & 2.821.975.531.355,00 & 2.821.975.531.355,00 & 272.765.582.640,69 \\
\hline
\end{tabular}

Fonte: Portal da Transparência do Governo Federal (2020b).

De modo geral, observa-se na Tabela 1, que as receitas realizadas por estes órgãos representam em 17 de abril de 2020, 10\% da arrecadação prevista para o ano. Esses dados podem alertar para possíveis impactos com a postergação e isenção de tributos decorrentes da COVID-19, e com a desaceleração da economia.

De modo a detalhar as receitas, são apresentados na sequência as subdivisões por categoria econômica de cada órgão do governo em análise. Conforme Tabela 2, as receitas previstas na LOA correspondem a $43 \%$ corrente (receitas provenientes de tributos, contribuições e transferências intra-orçamentárias), e 57\% de capital (receitas provenientes de operações de crédito, alienações de bens, amortização de empréstimos).

É importante observar que as receitas correntes e de capital intra-orçamentárias são aquelas realizadas entre órgãos e demais entidades da Administração Pública integrantes do orçamento fiscal e do orçamento da seguridade social do mesmo ente federativo (BRASIL, 2018).

As receitas realizadas até 17.04 .2020 , representam em torno de $11 \%$ das receitas previstas para 2020. Especificamente, pode-se observar que as realizadas correspondem a $15 \%$ das receitas correntes previstas, $11 \%$ das correntes intra-orçamentária, $8 \%$ das receitas de capital. Também foram realizadas receitas de capital intra-orçamentárias na ordem de $1 \%$.

Apesar de ainda incipiente para afirmar, pois os valores realizados são do primeiro quadrimestre, pode ser um indicativo de frustação de receita. Em comparação com o mesmo período de 2019, o percentual realizado em 2020 é baixo, ou seja, conforme consta no Relatório de Execução Orçamentária (2019), até abril daquele ano o governo federal já havia realizado $33 \%$ das receitas totais previstas (825.827.770 milhares de reais), representando $34 \%$ do previsto com receitas correntes, outros 32\% do previsto com receitas de capital, e $34 \%$ do previsto com receita corrente intra-oramentária (BRASIL, 2020a). A Tabela 2 apresenta as receitas correntes, correntes intra-orçamentária e de capital. 
Januário José Monteiro, Rodrigo Rengel, Fabricia Silva da Rosa, Rogério João Lunkes e Ana Paula Haskel

Tabela 2 - Resumo das Receitas previstas e realizadas por categoria econômica em 2020

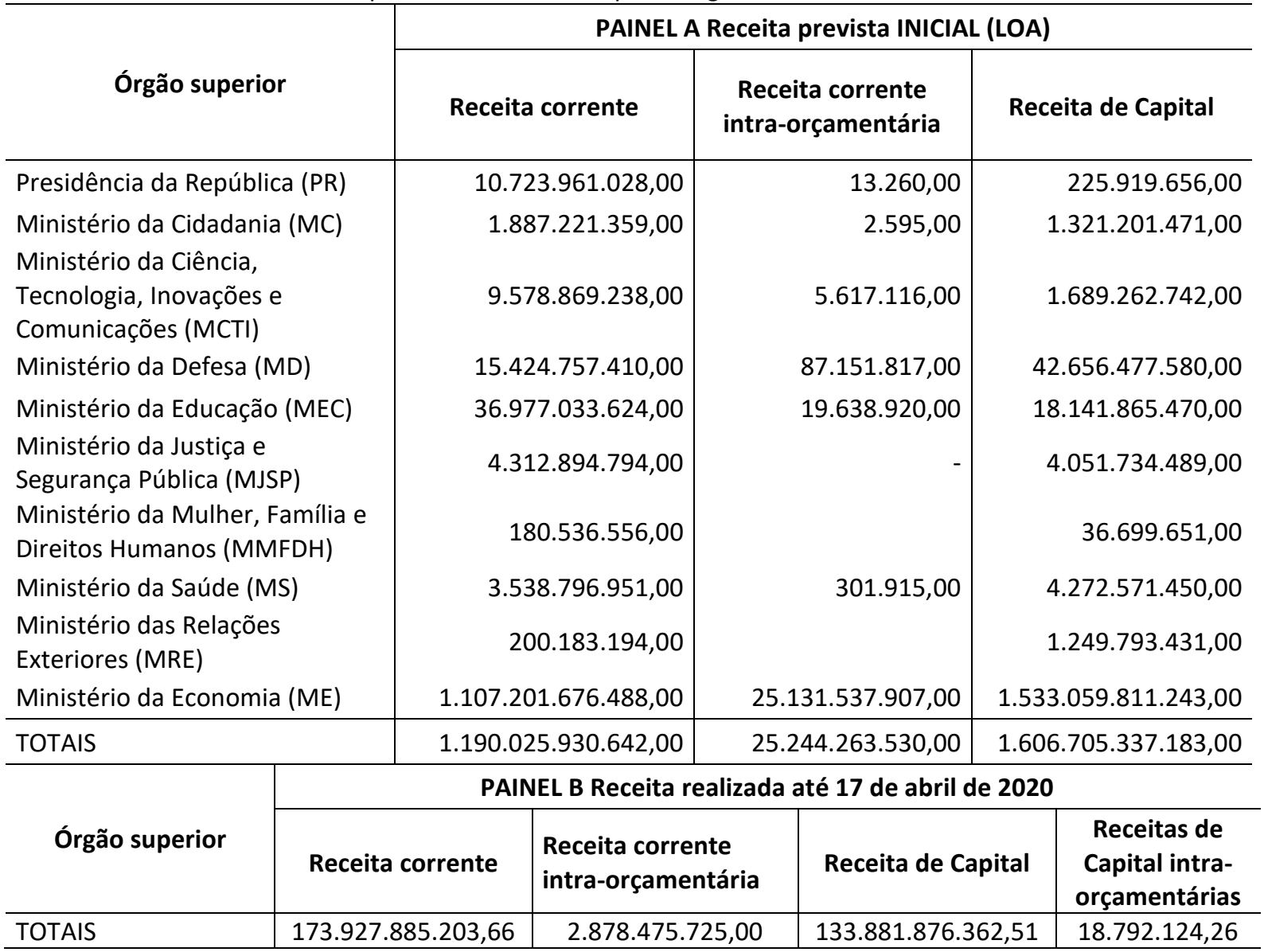

Fonte: Portal da Transparência do Governo Federal (2020b).

\subsection{ALTERAÇÕES NAS DESPESAS ORÇAMENTÁRIAS DO GOVERNO FEDERAL DEVIDO A PANDEMIA DA COVID-19}

O Governo Federal autorizou a abertura de créditos extraordinários no valor de R\$ 252,3 bilhões, por meio de medidas provisórias (MP's no 929, 935, 937, 939, 943, 959) para o combate aos impactos gerados pela pandemia da COVID-19. Essas MP's são autorizações para gastos de caráter urgente, e sua abertura independe de indicação prévia de fonte. Visam autorizar gastos com: Auxílio Emergencial a Pessoas em Situações de Vulnerabilidade (49\%), Ampliação do Programa Bolsa Família (1\%), Benefício Emergencial de Manutenção do Emprego e da Renda (20\%), Auxílio Emergencial aos Estados, Municípios e DF (6\%), Concessão de Financiamento para Pagamento de Folha Salarial (13\%), Transferência para a Conta de Desenvolvimento Energético (0,01\%), e Despesas Adicionais ao Ministério da Saúde e Demais Ministérios (9\%) (Agência Câmara de Notícias, 2020).

Verificou-se que as ações adotadas pelo governo refletiram no aumento das despesas anteriormente previstas na LOA 2020. Assim, apresenta-se na Tabela 3, as despesas decorrentes das ações para enfrentamento da pandemia da COVID-19. Essas informações são segregadas por órgão superior, a fim de possibilitar maior detalhamento do direcionamento dos recursos. 
Reflexos da COVID-19 no orçamento público do Governo Federal

Tabela 3 - Despesas públicas para o enfretamento conforme órgão superior do Governo Federal, destinadas ao combate da COVID-19 até 17 de abril de 2020.

\begin{tabular}{|c|c|c|c|}
\hline \multirow{2}{*}{ Órgão superior } & \multirow{2}{*}{$\begin{array}{c}\text { Dotação Inicial da } \\
\text { Despesa (LOA- } \\
\text { 2020) }\end{array}$} & \multicolumn{2}{|c|}{ Despesas decorrente da pandemia da COVID-19 } \\
\hline & & Despesas atualizadas & $\begin{array}{l}\text { Realizadas } \\
(17.04 .2020)\end{array}$ \\
\hline Presidência da República (PR) & $2.030 .167 .453,00$ & $54.838 .791,00$ & \\
\hline Ministério da Cidadania (MC) & $97.090 .587 .388,00$ & $98.250 .122 .957,37$ & $21.588 .457 .800,00$ \\
\hline $\begin{array}{l}\text { Ministério da Ciência, Tecnologia, } \\
\text { Inovações e Comunicações (MCTI) }\end{array}$ & $11.810 .348 .278,00$ & $100.000 .000,00$ & \\
\hline Ministério da Defesa (MD) & 73.069.108.757,00 & $231.287 .803,00$ & $5.297 .770,73$ \\
\hline Ministério da Educação (MEC) & 103.114.812.356,00 & $615.300 .715,00$ & $1.370 .593,08$ \\
\hline $\begin{array}{l}\text { Ministério da Justiça e Segurança } \\
\text { Pública (MJSP) }\end{array}$ & 13.909.243.687,00 & $199.824 .649,00$ & $131.003,49$ \\
\hline $\begin{array}{l}\text { Ministério da Mulher, Família e } \\
\text { Direitos Humanos (MMFDH) }\end{array}$ & $637.001 .870,00$ & $45.000 .000,00$ & \\
\hline Ministério da Saúde (MS) & 134.719.499.112,00 & 18.931.906.017,18 & $5.130 .660 .163,39$ \\
\hline $\begin{array}{l}\text { Ministério das Relações Exteriores } \\
\text { (MRE) }\end{array}$ & $2.266 .010 .508,00$ & $62.000 .000,00$ & 16.418.329,51 \\
\hline Ministério da Economia (ME) & $596.245 .498 .790,00$ & $34.000 .000 .000,00$ & $17.000 .000 .000,00$ \\
\hline Total das despesas com COVID-19 & \multicolumn{2}{|c|}{$152.490 .280 .932,55$} & $43.742 .335 .660,20$ \\
\hline Descrição & \multicolumn{2}{|c|}{ Atualizadas } & Realizadas \\
\hline Despesas total & \multicolumn{2}{|c|}{ 3.712.676.787.230,56 } & $976.165 .387 .234,85$ \\
\hline Repres. Das despesas com COVID-19 & \multicolumn{2}{|r|}{$4 \%$} & $4 \%$ \\
\hline
\end{tabular}

Fonte: Portal da Transparência do Governo Federal (2020a).

Conforme Tabela 3, percebe-se que as ações de enfrentamento a pandemia da COVID19 impactaram significativamente o orçamento. Conforme Lei no 13.978, de 17 de janeiro de 2020, previa incialmente uma despesa total de $\mathrm{R} \$ 3.565 .520 .100 .068,00$ (Brasil, 2020), no entanto, até a data de coleta dos dados já se observou um aumento de $\mathrm{R} \$$ 147.156.687.162,56. Essa variação se deve às diversas ações que estão sendo tomadas para amenizar o impacto da COVID-19. Essas ações são parte das políticas públicas que visam atender as necessidades da população em períodos de crise (HALEEM et al., 2020).

Observa-se também que a despesa total prevista será direcionada para os diferentes órgãos do Poder Executivo do Governo Federal, com o intuito de auxiliar o enfrentamento dos reflexos da pandemia nas diferentes áreas impactadas, sejam elas: social, economia ou política. Entre as despesas incluídas, destacam-se aquelas sob tutela do Ministério da Cidadania, que representa $64,43 \%$ do total das despesas previstas para combate à pandemia da COVID-19. Estes recursos estão sob o guarda-chuva de três programas orçamentários (Segurança alimentar e nutricional; Proteção social e Inclusão social por meio do bolsa família), cujas ações se subdividem em dois grupos. O primeiro grupo se refere as ações para auxílio emergencial de proteção social a pessoas em situação de vulnerabilidade, devido a pandemia da COVID-19, equivalente a R\$ 98 bilhões (98.200.000.000,37). O segundo se refere as ações de enfrentamento da emergência de saúde pública de importância internacional decorrente da COVID-19, e equivale a $R \$ 50$ milhões ( $R \$ 50.122 .957,00$ ). Essas ações foram apontadas por Tanne (2020) como sendo essenciais para a preservação dos direitos fundamentais à vida e a segurança social. Vale destacar que do total de despesas previstas para o Ministério da Cidadania, 22\% ( $\mathrm{R} \$ 21.588 .457 .800,00)$ até a data da coleta já haviam sido realizados. 
Destacam-se também as despesas sob responsabilidade do Ministério da Economia, que representam $22 \%$ do total previsto. Essas destinações ancoradas no programa operações especiais, visam a concessão de financiamentos para o pagamento da folha salarial, devido a pandemia da COVID-19, regulamentado pela Medida Provisória no 944. As despesas atualizadas equivalem a $R \$ 34$ bilhões, dos quais $R \$ 17$ bilhões até a data da coleta já haviam sido realizadas. A Secretaria Especial de Previdência e Trabalho (SEPRT) do Ministério da Economia disponibilizou o número de empregos preservados pelo Benefício Emergencial de Preservação do Emprego e da Renda (BEm), criado para por meio da MP no. 936/2020 para enfrentar os efeitos econômicos da pandemia da COVID-19, e amparado em termos de orçamento pela Medida Provisória-MP no 935/2020. O benefício é concedido a trabalhadores que tiverem jornada reduzida ou contrato suspenso, e ainda auxílio emergencial para trabalhadores intermitentes com contrato de trabalho formalizado. Como resultado, o governo aponta que 3.511.599 empregos já haviam sido preservados, com valores a serem pagos totalizando $\mathrm{R} \$$ 6.983.378.703,58, e acordos firmados por 569 mil empregadores (BRASIL, 2020r)

Medidas similares têm sido adotadas por outros países como EUA, com a isenção dos impostos sobre os salários (TANNE, 2020); na China, com a isenção do imposto sobre o valor agregado em diversos setores (KPMG CHINA; LU, 2020); e na Itália com auxílio aos funcionários demitidos (GOPINATH, 2020). Esses incentivos visam manter e estimular o consumo, ao mesmo tempo que demonstra a atenção às necessidades primárias da população.

Outro órgão superior que tem uma das maiores destinações de recursos para fazer frente à pandemia da COVID-19 é o Ministério da Saúde, que representa $12 \%$ do total das despesas previstas. Esses recursos estão ancorados no programa de atenção especializada à saúde, que visam o enfrentamento da emergência de saúde pública de importância internacional, decorrente da COVID-19. Com previsão equivalente a aproximadamente $R \$ 19$ bilhões ( $R \$ 18.931 .906 .017,18)$, sendo que já foram realizadas $27 \%$ desse total. Essas despesas foram despendidas em insumos como, leitos de UTI adulto, álcool, luvas, máscaras cirúrgicas, entre outros materiais. Além dessas ações do governo, o setor empresarial tem participado de maneira conjunta no combate a pandemia, por exemplo, por meio do Chamamento Público ME no 1/2020, 25 mil máscaras foram doadas, e segundo ao Ministério da Economia essa doação equivale a $\mathrm{R} \$ 1,4$ milhão de reais. Estas ações estão de certo modo alinhadas às apelações da OMS, no sentido de combater de maneira conjunto a COVID-19, quer por meio de cooperações internas quanto externas. A OMS elucida que o combate à pandemia é possível a partir de ações conjuntas como, ampliação do atendimento em saúde, assistência social e proteção econômica.

Os resultados das despesas do orçamento público do Governo Federal mostram que o maior montante não foi destinado diretamente a área da saúde, para cuidados com as pessoas infectadas pela COVID-19. Mas sim para manutenção do sistema social, destinado as pessoas com algum tipo de vulnerabilidade social. Isto mostra que em países subdesenvolvidos ou em desenvolvimento os sistemas sociais são pressionados, pois as pessoas deixam de ter recursos básicos para sua subsistência. Este processo se acelera quando há uma retração na economia, o que é um outro lado perverso dessa pandemia mundial.

De modo geral, percebeu-se que as ações do governo visam primeiro em atender as necessárias primárias da população, e primar pelos direitos fundamentais à vida, ao mesmo tempo que intervém na economia, de modo a estimular o consumo e preservar os empregos. 


\section{CONSIDERAÇÕES FINAIS}

O estudo teve por objetivo examinar os impactos da pandemia da COVID-19 no orçamento público do Governo Federal. Para alcançar este objetivo fez-se uma análise documental da Lei Orçamentária Anual (LOA, 2020), a Lei Complementar no 123, de 2006 e a Resolução CGSN no 140/18, e das Medidas Provisórias para abertura de créditos extraordinários, as MP's: 929, 935, 937, 939, 943, 959. Os dados referentes ao orçamento público, dos tributos, e das medidas provisórias foram obtidos no portal de transparência e no portal da Câmara dos Deputados do Governo Federal, no período de 17/04/2020 a 28/04/2020.

Os resultados evidenciam que o Governo Federal fez alterações dos prazos de vencimento do simples nacional e MEI (DAS) para 6 meses, referente à competência de março, abril e maio no tocante aos tributos federais. Essas medidas visaram incentivar as micro e pequenas empresas a manterem os negócios durante à pandemia. Também foram prorrogados os prazos das contribuições do PIS/Pasep e COFINS para 4 meses em relação a competência de março e 5 meses para a competência de abril, além da redução para zero da alíquota decorrente da venda de sulfato de zinco, das operações de crédito (IOF) e do IPI referente aos produtos descritos no Decreto no 10.302/2020. Estas ações objetivam incentivar as empresas a manterem os empregos dos trabalhadores.

Os resultados também apontaram impactos significativos nas despesas do orçamento público. O aumento da previsão das despesas para enfrentamento à COVID-19, representam $4 \%$ do total de despesas previstas no orçamento público. Grande parte destes recursos são direcionados ao Ministério da Cidadania para auxílio de pessoas em situação de vulnerabilidade (50\%), ao Ministério da Economia em vista da proteção do emprego e concessão de financiamento às empresas (33\%), e em torno de $17 \%$ especificamente para a saúde. Sendo que os recursos do Ministério da Saúde e secretarias estaduais e municipais de saúde são para aquisição de insumos para assistência médica aos infectados pela pandemia da COVID-19.

A pesquisa gera implicações ao revelar que em momento de crise a intervenção e participação do estado na economia precisa ser notória por diversos motivos. Primeiro, por permitir que os direitos essenciais à vida sejam salvaguardados, a partir das ações de cidadania. Segundo, por resguardar o emprego, permitindo o não aumento da taxa de desemprego. E terceiro por incentivar a cooperação interna e externa em vista da busca por soluções tempestivas. De certo modo, esta pesquisa gera implicações teóricas ao sugerir que as políticas públicas adotadas em fase de crise são escolhas que podem auxiliar na busca por soluções diante de uma crise.

Como limitações destaca-se a tempestividade do estudo, ou seja, como o estudo se baseia em dados atualizados até o mês de abril, alguns reflexos de execução da receita e da despesa não podem ser captados, visto que a pandemia COVID-19 está ocorrendo e seus impactos na saúde, economia e sociedade ainda não são bem conhecidos, o que dificulta previsões de médio e longo prazo. Neste estudo foi dada maior atenção à perspectiva da gestão financeira, enquanto estudos futuros podem avaliar com maior profundidade a dimensão do planejamento do orçamento público.

Uma vez que o estudo se limitou à compreensão dos impactos da pandemia COVID-19 nos tributos federais, sugere-se para pesquisas futuras analisarem outros tributos como estaduais e municipais. Ao verificar os impactos da COVID-19 no orçamento público, especificamente nas receitas e despesas, deu-se maior atenção para aquelas que se 
mostraram mais representativas. Futuras pesquisas podem examinar as destinações aos programas de enfrentamento da COVID-19, a eficiência na aplicação de recursos, bem como reflexos e riscos fiscais futuros (como por exemplo aumento da dívida pública). Outra sugestão seria uma maior atenção as questões previdenciárias.

\section{REFERÊNCIAS}

AGÊNCIA CÂMARA DE NOTÍCIAS. Recursos previstos em medidas provisórias contra a pandemia de Covid-19 já somam 252,3 bi. 2020. Disponível em:

https://www.camara.leg.br/noticias/657114-recursos-previstos-em-medidas-provisoriascontra-a-pandemia-de-covid-19-ja-somam-2523-bi/. Acesso em: 10 abr. 2020.

BRASIL. Manual de Contabilidade Aplicada ao Setor Público. 8. ed. 2018. Disponível em https://www.tesourotransparente.gov.br/publicacoes/manual-de-contabilidade-aplicadaao-setor-publico-mcasp/2019/26. Acesso em: 10 abr. 2020.

ATLURI, S.; MANCHIKANTI, L.; HIRSCH, J. A. Expanded Umbilical Cord Mesenchymal Stem Cells (UC-MSCs) as a therapeutic strategy in managing critically III COVID-19 Patients: The Case for Compassionate Use. Pain Physician, v. 23, n.2, p. 71-83, 2020.

BALDWIN, R.; DI MAURO, B. W. Mitigating the COVID Economic Crisis: Act Fast and Do Whatever It Takes. A VoxEU.org Book. CEPR Press, 2020.

BALDWIN, R. Keeping the lights on: Economic medicine for a medical shock. Macroeconomics, v. 20, p. 1-20, 2020.

BRASIL. Lei ${ }^{\circ}$ 4.320, de 17 de março de 1964. 1964. Disponível em: http://www.planalto.gov.br/ccivil_03/leis/14320.htm. Acesso em: 17 abr. 2020.

BRASIL. Decreto-Lei no 200, de 25 de fevereiro de 1967. 1967. Disponível em: http://www.planalto.gov.br/ccivil_03/decreto-lei/del0200.htm. Acesso em: 17 abr. 2020.

BRASIL. Constituição da República Federativa do Brasil de 1988. 1988. Disponível em: http://www.planalto.gov.br/ccivil_03/constituicao/constituicao.htm. Acesso em: 17 abr. 2020.

BRASIL. Lei no 9.718, de 27 de novembro de 1998. 1998. Disponível em: http://www.planalto.gov.br/ccivil_03/leis/I9718compilada.htm. Acesso em: 17 abr. 2020.

BRASIL. Lei $\mathbf{n}^{0}$ 10.637, de 30 de dezembro de 2002. 2002. Disponível em: http://www.planalto.gov.br/ccivil_03/leis/2002/l10637.htm. Acesso em: 17 abr. 2020.

BRASIL. Lei $\mathbf{n}^{\circ} \mathbf{1 0 . 8 3 3}$, de 29 de dezembro de 2003. 2003. Disponível em: http://www.planalto.gov.br/ccivil_03/leis/2003/L10.833.htm. Acesso em: 17 abr. 2020.

BRASIL. Lei complementar no 123, de 14 de dezembro de 2006. 2006. Disponível em: http://www.planalto.gov.br/ccivil_03/leis/lcp/lcp123.htm. Acesso em: 17 abr. 2020. 
BRASIL. Resolução CGSN no 140, de 22 de maio de 2018. 2018. Disponível em: http://normas.receita.fazenda.gov.br/sijut2consulta/link.action?idAto=92278. Acesso em: 17 abr. 2020.

BRASIL Orçamento do Governo Federal: Créditos Adicionais. Câmara do Deputados. 2020a. Disponível em: https://www2.camara.leg.br/orcamento-da-uniao/leisorcamentarias/creditos. Acesso em: 27 abr. 2020.

BRASIL. Confira as medidas tomadas pelo Ministério da Economia em função da Covid-19 (Coronavírus). 2020b. Disponível em: https://www.gov.br/economia/pt$\mathrm{br} /$ assuntos/noticias/2020/marco/confira-as-medidas-tomadas-pelo-ministerio-daeconomia-em-funcao-do-covid-19-coronavirus. Acesso em: 27 abr. 2020.

BRASIL. Decreto no 10.302, de 10 de abril de 2020. 2020c. Disponível em: http://www.planalto.gov.br/ccivil_03/_ato2019-2022/2020/decreto/D10302.htm. Acesso em: 27 abr. 2020.

BRASIL. Decreto no 10.305, de 10 de abril de 2020. 2020d. Disponível em: http://www.planalto.gov.br/ccivil_03/_ato2019-2022/2020/decreto/D10305.htm. Acesso em: 27 abr. 2020.

BRASIL. Decreto no 10.318, de 9 de abril de 2020. 2020e. Disponível em: http://www.planalto.gov.br/ccivil_03/_ato2019-2022/2020/decreto/D10318.htm. Acesso em: 27 abr. 2020.

BRASIL. Emenda Constitucional no 106, de 7 de maio de 2020. 2020f. Disponível em: http://www.planalto.gov.br/ccivil_03/Constituicao/Emendas/Emc/emc106.htm. Acesso em: 27 abr. 2020.

BRASIL. Lei no 13.978, de 17 de janeiro de 2020. 2020g. Disponível em: http://www.planalto.gov.br/ccivil_03/_ato2019-2022/2020/lei/l13978.htm. Acesso em: 18 abr. 2020.

BRASIL. Lei no 13.979, de 6 de fevereiro de 2020. 2020h. Disponível em: http://www.planalto.gov.br/ccivil_03/_ato2019-2022/2020/lei/L13979.htm. Acesso em: 18 abr. 2020.

BRASIL. Medida Provisória no 929, de 25 de março de 2020. 2020i. Disponível em: http://www.planalto.gov.br/ccivil_03/_Ato2019-2022/2020/Mpv/mpv929.htm. Acesso em: 18 abr. 2020.

BRASIL. Medida provisória no 935, de 10 de abril de 2020. 2020j. Disponível em: http://www.planalto.gov.br/ccivil_03/_Ato2019-2022/2020/Mpv/mpv935.htm. Acesso em: 18 abr. 2020. 
BRASIL. Medida Provisória no 936, de 10 de abril de 2020. 2020k. Disponível em: http://www.planalto.gov.br/ccivil_03/_Ato2019-2022/2020/Mpv/mpv936.htm. Acesso em: 18 abr. 2020.

BRASIL. Medida Provisória no 937, de 2 de abril de 2020. 2020l. Disponível em: http://www.planalto.gov.br/ccivil_03/_Ato2019-2022/2020/Mpv/mpv937.htm. Acesso em: 20 abr. 2020.

BRASIL. Medida Provisória no 939, de 2 de abril de 2020. 2020m. Disponível em: http://www.planalto.gov.br/ccivil_03/_Ato2019-2022/2020/Mpv/mpv939.htm. Acesso em: 20 abr. 2020.

BRASIL. Medida Provisória no 943, de 3 de abril de 2020. 2020n. Disponível em: http://www.planalto.gov.br/ccivil_03/_Ato2019-2022/2020/Mpv/mpv943.htm. Acesso em: 20 abr. 2020.

BRASIL. Medida Provisória no 959, de 29 de abril de 2020. 2020o. Disponível em: http://www.planalto.gov.br/ccivil_03/_ato2019-2022/2020/Mpv/mpv959.htm. Acesso em: 20 abr. 2020.

BRASIL. Portaria no 136, de 15 de janeiro de 2020. 2020p. Disponível em: http://www.in.gov.br/web/dou/-/portaria-n-136-de-15-de-janeiro-de-2020-238771165. Acesso em: 20 abr. 2020.

BRASIL. Resolução CGSN no 154, de 03 de abril de 2020. 2020q. Disponível em: http://normas.receita.fazenda.gov.br/sijut2consulta/link.action?visao=anotado\&idAto=1083 68. Acesso em: 15 abr. 2020.

BRASIL. Número de empregos preservados pelo BEM já pode ser consultado online. 2020r. Disponível em: https://www.gov.br/economia/pt-br/assuntos/noticias/2020/abril/numerode-empregos-preservados-pelo-bem-ja-pode-ser-consultado-online. Acesso em: 15 abr. 2020.

CALLAWAY, E. Time to use the $p$-word? Coronavirus enter dangerous new phase. Nature, v. 579, n. 277, p. 1-12, 2020. Disponível em: https://www.nature.com/articles/d41586-02000551-1. Acesso em: 15 abr. 2020.

CANDEAIS V.; MORHARD R. The human costs of epidemics are going down but the economic costs are going up. Here's why. 2018. Disponível em: https://www.weforum.org/agenda/2018/05/how-epidemics-infect-the-global-economyand-what-to-do-about-it/. Acesso em: 15 abr. 2020.

CHIOLERO, A. COVID-19: a digital epidemic. BMJ, v. 368, p.764, 2020. DOI: https://doi.org/10.1136/bmj.m764.

DJALANTE, R.; LASSA, J.; SETIAMARGA, D.; MAHFUD, C.; SUDJATMA, A.; INDRAWAN, M.; HARYANTO, B.; MAHFUD, C.; SINAPOY, M. S.; DJALANTE, S.; RAFLIANA, I.; GUNAWAN, L. A. 
SURTIARI, G. A. K.; WARSILAH, H. Review and analysis of current responses to COVID-19 in Indonesia: Period of January to March 2020. Progress in Disaster Science, v. 6, p. 1-37, 2020. DOI: https://doi.org/10.1016/j.pdisas.2020.100091.

GASPAR, V.; MAURO, P. Fiscal Policies to Protect People During the Coronavirus Outbreak. IMF Blog, 5. 2020. Disponível em: https://blogs.imf.org/2020/03/05/fiscal-policies-toprotect-people-during-the-coronavirus-outbreak/. Acesso em: 10 abr. 2020.

GOPINATH, G. 3 Limiting the economic fallout of the coronavirus with large targeted policies. Mitigating the COVID Economic Crisis: Act Fast and Do Whatever, p. 1-41, 2020. Disponível e: https://blogs.imf.org/2020/03/09/limiting-the-economic-fallout-of-thecoronavirus-with-large-targeted-policies/. Acesso em: 10 abr. 2020.

HALEEM, A.; JAVAID, M.; VAISHYA, R.; DESHMUKH, S. G. Areas of academic research with the impact of COVID-19. The American Journal of Emergency Medicine, v. 38, n. 7, 1524-1526, 2020. DOI: https://doi.org/10.1016/j.ajem.2020.04.022.

K.P.M.G. CHINA; LU, L. China announces tax relief measures to tackle coronavirus disruption. International Tax Review, 2020. Disponível em:

https://www.internationaltaxreview.com/article/b1kjjn20mxcfyj/china-announces-taxrelief-measures-to-tackle-coronavirus-disruption. Acesso em: 10 abr. 2020.

LEITE FILHO, G. A.; CRUZ, C. F.; SILVA, T. G.; DE BRITO NASCIMENTO, J. P. Relação entre a qualidade da gestão fiscal e a transparência dos municípios brasileiros. Cadernos Gestão Pública e Cidadania, v. 23, n. 76, 2018. DOI: http://dx.doi.org/10.12660/cgpc.v23n76.75408.

OMS. Coronavirus (COVID-19). 2020. Disponível em: https://covid19.who.int/. Acesso em: 10 abr. 2020.

PORTAL DA TRANSPARÊNCIA. Orçamento da despesa. 2020a. Disponível em: http://www.portaltransparencia.gov.br/download-de-dados/orcamento-despesa. Acesso em: 17 abr. 2020.

PORTAL DA TRANSPARÊNCIA. Receitas. 2020b. Disponível em: http://www.portaltransparencia.gov.br/download-de-dados/receitas. Acesso em: 17 abr. 2020.

RAFAELL, R. D. M. R.; NETO, M.; CARVALHO, M. M. B. D.; DAVID, H. M. S. L.; ACIOLI, S.; FARIA, M. G. D. A. Epidemiologia, políticas públicas e pandemia de Covid-19: o que esperar no Brasil? Revista de Enfermagem UERJ, Rio de Janeiro, v. 28, p. 49-570, 2020. DOI: https://doi.org/10.12957/reuerj.2020.49570.

SAWHNEY, U. An Analysis of Fiscal Policy in an Emerging Economy: Innovative and Sustainable Fiscal Rules in India. Millennial Asia, v. 9, n. 3, p. 295-317, 2018. DOI: https://doi.org/10.1177/0976399618805629. 
Januário José Monteiro, Rodrigo Rengel, Fabricia Silva da Rosa, Rogério João Lunkes e Ana Paula Haskel

TANNE, J. H. COVID-19: Trump proposes tax cuts and improved health insurance, but millions are not covered. BMJ, New York, 368:m993, 2020. DOI:

https://doi.org/10.1136/bmj.m993.

XIANG, Y. T.; LI, W.; ZHANG, Q.; JIN, Y.; RAO, W. W.; ZENG, L. N.; LOK, G. K. I.; CHOW, I. H. I.; CHEUNG, T.; HALL, B. J. Timely research papers about COVID-19 in China. The Lancet, v. 395, n. 10225, p. 684-685, 2020. DOI: https://doi.org/10.1016/S0140-6736(20)30375-5. 